\title{
No differences in histopathological degenerative changes found in acute, trauma-related rotator cuff tears compared with chronic, nontraumatic tears
}

\author{
Knut E. Aagaard ${ }^{1,2}$ (1) $\cdot$ Hanna Cecilia Björnsson Hallgren ${ }^{3} \cdot$ Karl Lunsjö $^{1} \cdot$ Richard Frobell $^{2}$
}

Received: 21 September 2021 / Accepted: 12 January 2022 / Published online: 8 February 2022

(c) The Author(s) 2022

\begin{abstract}
Purpose Acute trauma-related rotator cuff tears are believed to have better healing potential than chronic tears due to less degenerative changes of the tendons. However, the histopathological condition of tendons from trauma-related tears is not well investigated. The purpose of this study was to explore specific histopathological features in tendons from acute traumarelated full-thickness rotator cuff tears and to compare them to findings in tendons from nontraumatic, chronic tears.

Methods In a prospective cohort study, 62 previously asymptomatic patients [14 women, median age 61 years (range 42-75)] with trauma-related full-thickness rotator cuff tears were consecutively included. Arthroscopic repair was performed within 30 (median, IQR 25-37) days after the injury. During surgery, tissue biopsies were harvested from the supraspinatus tendons in $53(86 \%)$ of the patients. In addition, similar biopsies were harvested from 10 patients undergoing surgery for chronic tears without history of trauma. All tissue samples were examined by a well-experienced pathologist under light microscope. Tendon degeneration was determined using the Bonar score whereas immunostaining was used for proliferation (Ki67), inflammation (CD45), apoptosis (p53) and haemosiderin staining to study traces of bleeding.

Results The median (IQR) Bonar score for the acute trauma-related biopsies was 10.5 (7.5-14.5) compared to 11 (5-12.8) for the control group with no statistically significant difference between the groups. No statistically significant between-group difference was found for the inflammatory index whereas tendons from patients with trauma-related full-thickness rotator cuff tears had statistically significantly higher apoptosis [3.1 (0.5-8.9) vs. $0.1(0-1.5), p=0.003]$ and proliferation [4.0 (1.8-6.9) vs. $0.4(0-2.0), p=0.001)$ indices than those undergoing surgery for chronic tears. Positive haemosiderin staining was found in $34 \%$ of tissue samples from patients with trauma-related tears compared to $10 \%$ in the control group (n.s).

Conclusion This study suggests that there is no difference with regard to degenerative changes between supraspinatus tendons harvested from patients with acute, trauma-related rotator cuff tears and patients with nontraumatic, chronic tears.

Level of evidence II.
\end{abstract}

Keywords Shoulder $\cdot$ Rotator cuff $\cdot$ Acute rotator cuff tear · Trauma-related rotator cuff tear $\cdot$ Histopathology $\cdot$ Tendon degeneration $\cdot$ Arthroscopy $\cdot$ Supraspinatus tendon $\cdot$ Apoptosis

\section{Introduction}

Knut E. Aagaard

knut.aagaard@gmail.com

1 Department of Orthopaedics, Helsingborg Hospital, Region Skåne, Sweden

2 Orthopedics, Clinical Sciences Lund, Lund University, Lund, Sweden

3 Department of Orthopaedics in Linköping and Department of Biomedical and Clinical Sciences, Linköping University, S-58185 Linköping, Sweden
Pain and shoulder dysfunction are common in the general population where rotator cuff tendinopathy and rotator cuff tears (RCT) represent the most common cause of these conditions [36, 43]. A clear pathogenesis is yet to be determined but, a combination of intrinsic and extrinsic factors, gradually leading to weakening of the connective tissue leaving the tendon prone to tearing, is agreed upon [46]. Kannus and Józsa suggested already 1991 that tendon rupture is closely associated with preceding histopathological changes [19] which is supported by later studies reporting high prevalence of 
asymptomatic supraspinatus tears [24, 31, 33, 40, 48]. Despite this suggested overall degenerative genesis of rotator cuff tears, trauma-related tears are often studied and discussed as acute injuries and separated from chronic, nontraumatic tears [13, $29,34,38,42,50]$. In trauma-related tears, early surgical repair is often advocated with the argument of superior healing properties and the advancing muscle atrophy and fatty infiltration $[9,13,34,43]$.

Although diagnostic methods and surgical techniques have developed significantly over the last decade, non-healing and retear rates of surgically repaired tendons are still unacceptably high $[6,15,16,35,37]$. This has led to a growing interest in aetiology of tendon tearing and biology of healing. Tendon degeneration may be estimated using magnetic resonance imaging (MRI) and ultrasound as proxies, however, histopathology of harvested biopsies from torn tendons is gold standard in determining tendon degeneration. Still, results from such trials are scarce. After a trauma-related tear, tendons are suggested to respond with a three-stage tissue healing process including an initial inflammatory phase followed by proliferative and remodelling phases [17]. Rotator cuff tendons are, however, intra-synovial and it is not known if intra-synovial tendons undergo similar healing processes as extra-synovial tendons. Nevertheless, tissue damage will most likely induce an inflammatory reaction, yet the optimal degree of inflammatory and proliferative response to facilitate healing is unknown. Apoptosis is a physiological process in healthy tissue of importance to maintain proper homeostasis. However, the role and extent of apoptosis in tissue degeneration and cuff tendon tearing is not clear and has to our knowledge not been specifically studied in trauma-related tears [3, 26, 32, 44, 49]. Further, we hypothesised that traumatic tears would show signs of bleeding that could be detected by haemosiderin staining.

Hence, the primary purpose of this study was to determine the degree of tendon degeneration in trauma-related tears with acute symptoms using the Bonar score and to compare these findings to tendons from a matched controlled group encompassing only nontraumatic, chronic tears. Secondary purposes were to study and compare the rate of inflammation, proliferation, apoptosis, and haemosiderin staining. Increased knowledge about histopathological changes and possible pre-existing tendon weakening found in previously shoulder healthy patients suffering from acute, trauma-related tears would improve the process to provide the best individual treatment.

\section{Materials and methods}

\section{Patients' selection and study design}

This study involved patients included in a prospective shoulder cohort study conducted at Helsingborg Hospital in southern Sweden [1]. The study was performed in accordance with the ethical standards of the Helsinki Declaration and approved by the regional ethical review board in Lund, Sweden, registration number DNR 2011/119, 2015/36, 2016/796. Previously subjective shoulder healthy patients, aged $18-75$ years, presenting at the orthopaedic or emergency department with shoulder pain, limited rotator cuff-specific shoulder function and normal plain radiographs following a direct or an indirect trauma to their shoulders formed the trauma-related group and were included in this trial between November 2010 and March 2014 [1]. Exclusion criteria were: preinjury shoulder complaints, rheumatoid arthritis, severe comorbidity or previous surgery to the affected shoulder. Diagnostic MRI was conducted within 19 (median, IQR 15-24) days after the traumatic event using the same 1.5 T scanner (Siemens Medical Systems, Erlangen, Germany) with a dedicated shoulder array coil and without contrast enhancement (Appendix I). A full-thickness RCT was defined as a discontinuity in the tendon or increased signal on T2-weighted images extending from the articular to the bursal side of the tendon [18]. All included patients were offered, and underwent, arthroscopic repair. In one of the cases, a partial repair was performed.

Surgery was performed at a median of 30 (IQR 25-37) days after the shoulder injury. All surgical procedures were carried out at the Department of Orthopaedics at Helsingborg Hospital and were performed by one of three wellexperienced shoulder surgeons. During surgery, and before any radio frequency instruments was used, a biopsy of the most lateral part of the torn supraspinatus tendon was harvested in a standardised fashion using a meniscus upbiter basket punch. The tissue material was then fixed in neutral buffered formalin, transported to the Department of Pathology at Lund University where it was dehydrated and paraffin embedded. Sections of $2 \mu \mathrm{m}$ were obtained and stained with haematoxylin-eosin (HE) and Alcian blue (AB). Sections were then scanned by Nano Zoomer S360 (Hamamatsu, Japan) and evaluated for tendon degeneration. Out of the 62 included patients that underwent surgery, 6 had intact supraspinatus tendons (isolated subscapularis tendon tears) and in 3 cases, the surgeon neglected to harvest a supraspinatus tendon biopsy leaving 53 samples for analysis. In addition, similar tissue samples were harvested from ten age- and sex-matched individuals with no history of shoulder trauma undergoing surgery for chronic rotator cuff tears. These samples formed the control group referred to as the chronic tears in this report (Table 1).

\section{Tendon degeneration as determined by histopathology: the Bonar score}

The Bonar score was used to evaluate the extent of tendon degeneration [10]. This score comprises a semi-quantitative 
Table 1 Patient demographics

\begin{tabular}{lll}
\hline & $\begin{array}{l}\text { Study group } \\
n=53\end{array}$ & $\begin{array}{l}\text { Control group } \\
n=10\end{array}$ \\
\hline Age, years (median, range) & $61(43-75)$ & $64.5(41-75)$ \\
Male sex (\%) & 81 & 70 \\
Diabetes ( $n, \%)$ & $4(8)$ & $1(10)$ \\
BMI (median, IQR) & $28(25-30)$ & $29(26-30)$ \\
Smoking (n, \%) & $6(11)$ & $3(30)$ \\
\hline
\end{tabular}

grading scale that emphasises seven pathological qualities in tendinosis: fibroblastic alterations (hyper-/hypocellularity), increased glycosaminoglycan content, collagen disorganisation or disarray, hypervascularity or vascular remodelling, cell morphology, calcification, and intratendinous adipocytes. HE stains of $2-\mu \mathrm{m}$ sections were obtained for assessment of the morphology. AB stains were performed for identification of sulfated glycosaminoglycans (GAG). The first five qualities were graded from 0 to 3 (normal to worst pathological appearance), and the presence of calcification and adipocytes are each given 2.5 points. A completely normal tendon would score 0 and accordingly, a maximally degenerated tendon would score $20(3 \times 5+2.5 \times 2$, Appendix II $)$. The latest modified Bonar score with previously reported good inter-observer reliability $\left(r^{2}=0.71\right)$ was used [10]. All tissue samples were analysed by an experienced pathologist at the Department of Pathology, Lund University.

\section{Immunohistochemistry}

The immunohistochemical tests were conducted at the Department of Pathology, Lund University. To evaluate the degree of inflammatory response, the expression of the pan-leucocyte marker CD45 was studied [8]. The pathologist manually marked out the borders of the entire section where counting of stain positive cells was conducted by a computer-based software (Sectra IDS7 Px, Sectra, Sweden) [21]. The inflammatory index was defined as the number of all CD45-positive cells per $\mathrm{mm}^{2}$.

Tendon proliferation response and activity was estimated by calculating the proliferation index [27], defined as the percentage of all Ki-67-positive cells within all fields of a given region of interest (ROI) that showed positive labelling. The pathologist visually inspected the entire section and localised a "hotspot" (i.e. the area of maximum staining) which defined the ROI. Within this ROI, counting of cells was conducted by a computer-based software (Sectra) [21].

For the assessment of apoptosis, the expression of p53 was studied. The apoptotic (p53) index was calculated and defined as the percentage of all positive p53 cells within all fields of a given tissue sample that showed positive labelling (number of positive cells/total number of all cells $\times 100$ ).
Here, the hotspot technique (described above) was used by the pathologist for defining the ROI.

To detect haemosiderin deposition, histochemical staining with Perls' Prussian blue was used. No intensity scores were used; thus, any detected deposits within all fields of the tissue sample were considered positive.

Intra-observer reliability testing using intraclass correlation coefficient showed good to excellent agreement for Bonar score $(\mathrm{ICC}=0.97), \mathrm{p} 53(\mathrm{ICC}=0.96), \mathrm{Ki} 67$ $(\mathrm{ICC}=0.99)$, and CD45 $(\mathrm{ICC}=0.99)$ as shown in Table 2.

\section{Statistical analysis}

More than $50 \%$ of the variables were not normal distributed, and thus, median and interquartile range (IQR) is reported for all variables and nonparametric tests were used for statistical analyses. The Mann-Whitney $U$ test was used for between-group comparisons, and linear regression analyses were used to study the relationship between degeneration and immunohistochemistry outcomes in the study group. Fisher exact test was used to compare the frequencies of positive haemosiderin labelling between the two groups. Intra-observer reliability was tested using the intraclass coefficient (ICC) calculation with two-way random-effects model. As suggested, an ICC below 0.50 was considered as poor reliability, between 0.50 and 0.75 moderate, between 0.75 and 0.90 good, and above 0.90 excellent reliability [22]. Significance level of $5 \%$ was considered to determine statistical significance. Statistical analyses were performed using SPSS version 24 (IBM Corp., Armonk, New York). A power calculation for the trial was done based on an $80 \%$ proportion of successful healing of repaired cuffs (regardless of number of involved tendons, primary outcome) was performed and reported [1].

\section{Results}

The median Bonar score for patients with trauma-related tears (Fig. 1) and patients with chronic tears was 10.5 (IQR 7.5-14.5) and 11 (IQR 5-12.8), respectively, with no statistically significant difference between the groups (Table 3). There were large variations with regard to the

Table 2 Intra-observer reliability testing ICC

\begin{tabular}{llll}
\hline & $\begin{array}{l}\text { Intraclass cor- } \\
\text { relation }\end{array}$ & $\begin{array}{l}\text { 95\% Confidence } \\
\text { interval }\end{array}$ & $p$ value \\
\hline Bonar score & 0.97 & $0.89-0.99$ & $<0.001$ \\
p53 & 0.96 & $0.85-0.99$ & $<0.001$ \\
Ki67 & 0.99 & $0.99-1.00$ & $<0.001$ \\
CD45 & 0.99 & $0.95-1.00$ & $<0.001$ \\
\hline
\end{tabular}


inflammatory index in both groups, and no statistically significant between-group difference was found [2.3 (IQR $0.1-10.1$ ) vs. 4.5 (IQR, $0.1-13.6)]$. The proliferation and the apoptotic (p53) indices were statistically significantly higher in patients with trauma-related tears compared to patients with chronic tears $(p=0.001$ and $p=0.003$, respectively, Table 3). In the study group with trauma-related tears, the linear regression model showed a statistically significant relation between higher Bonar score and higher inflammatory index $(B=0.11,95 \%$ CI $[0.06,0.16], p<0.001)$ and higher apoptotic (p53) index $(B=0.13,95 \%$ CI [0.01, 0.25], $p=0.04$ ). A positive labelling for haemosiderin was found in 18 of the 53 (34\%) tissue samples of patients with traumarelated tears compared to 1 of $10(10 \%)$ in patients with chronic tears (n.s).

\section{Discussion}

The main finding in this first report on histopathological changes found in acute, trauma-related rotator cuff tears, was a high degree of tendon tissue degeneration. Interestingly, the degree of degeneration in the torn supraspinatus of the study cohort did not statistically significantly differ from degenerative findings in a control group with nontraumatic chronic tears. The reported high degree of tendon tissue degeneration is in accordance with Codman's theory postulating a pre-existing tendon weakness [11]. Even though trauma may elicit an RCT, our findings support that patients with acute shoulder symptoms after a traumatic event, may have had a substantial tendon degeneration despite being asymptomatic before the injury.

Tissue damage and haemorrhage initiate an inflammatory phase, the important first step of an attempted healing
Table 3 Histopathological findings in study group compared to the control group (median, IQR)

\begin{tabular}{lll}
\hline & $\begin{array}{l}\text { Study group } \\
n=53\end{array}$ & $\begin{array}{l}\text { Control group } \\
n=10\end{array}$ \\
\hline Bonar score & $10.5(7.5-14.5)$ & $11(5-12.8)$ \\
Cell morphology & $2(1-3)$ & $2(1-2)$ \\
Collagen arrangement & $2(1-3)$ & $2(1-2)$ \\
Cellularity & $2(1-2)$ & $1.5(1-2)$ \\
Vascularity & $1(0-3)$ & $0.5(0-2.3)$ \\
Ground substance & $2(2-2)$ & $2(1.8-2)$ \\
Calcification, $n(\%)$ & $16(31)$ & $4(40)$ \\
Adipocytes*, $n(\%)$ & $17(33)$ & $3(30)$ \\
Inflammatory index & $2.3(0.1-10.1)$ & $4.5(0.1-13.6)$ \\
Proliferation index & $4.0(1.8-6.9)$ & $0.4(0-2.0)$ \\
Apoptotic index $(\mathrm{p} 53)$ & $3.1(0.5-8.9)$ & $0.1(0-1.5)$ \\
Haemosiderin staining $+\%(n)$ & $34(18 / 53)$ & $10(1 / 10)$ \\
\hline
\end{tabular}

*Intratendinous

process $[4,14,17]$. Prerequisites of inflammation are hematoma, deposition of fibrin, cytokine, growth factors release leading to migration of fibroblasts and endothelial cells and the inflammatory phase lasts for about 1 week $[2,12]$. The large variation in inflammatory index found in our study could possibly be explained by biopsies being harvested at various time points over the first 6 weeks after trauma. Still, post hoc sensitivity analyses failed to find any relations between inflammatory index and age, time from injury, tear size or BMI (data not shown). The inflammatory response needs to be activated for healing to take place [17]; however, its role is most likely diverse in different phases of the healing process and the optimal level of inflammation to facilitate healing is not known. Several studies have reported

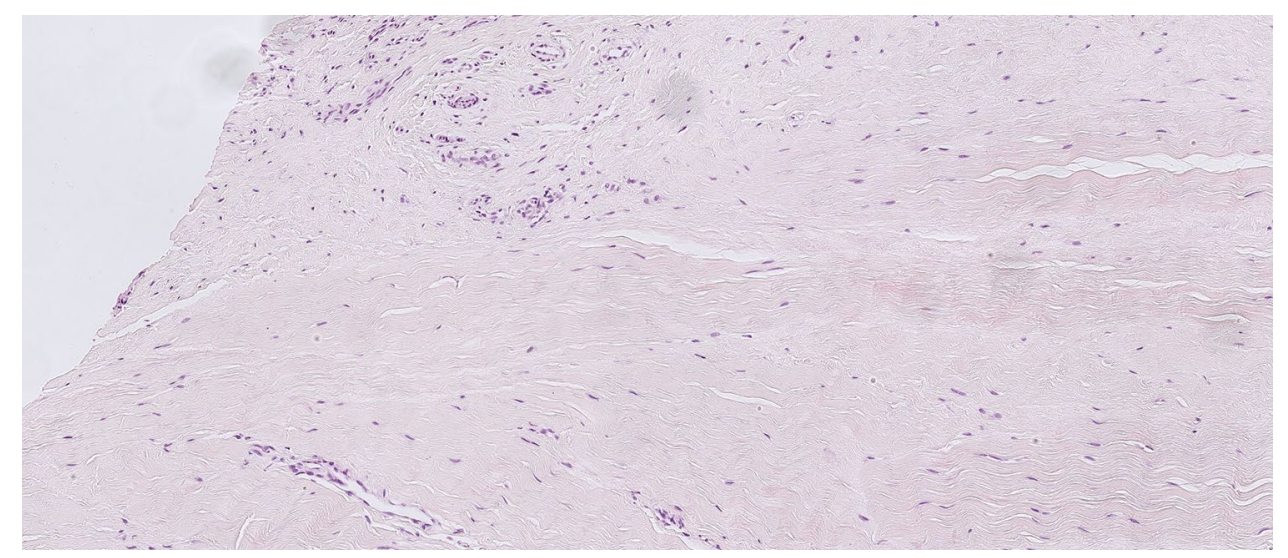

Fig. 1 Hematoxylin and eosin stain of supraspinatus tendon harvested from the lateral edge of the tear stump in a 59-year-old woman (original magnification: $\times 400$ ). Cell morphology: increased roundness, 1 ; collagen alignment: separation of individual fibre bundles, 1 ; cellular- ity: hypercellularity, 1; vascularity: areas of several clusters of vessels, 3; ground substance: moderate stainable GAG (graded on Alcian blue stain), 2; no calcification, 0; adipocytes detected, 2.5. Total Bonar score 10.5 
that corticosteroids downregulate the inflammatory response and that this is deleterious to healing and repair strength [20, 30, 39, 44]. In this study, however, none of the patients received pre- or post-injury corticosteroid injections. Studies on Achilles tendons have reported that prolonged inflammation has a negative impact on healing as it disturbs the following proliferation and remodelling phases [4]. In addition, severe inflammation in normal wound healing is associated with excessive scarring [47]. Consequently, a disproportionate, pre-existing inflammation with additional inflammatory response induced by surgery may influence the healing negatively and may also induce adherences or capsulitis.

During tendon healing, the transition from inflammation to proliferation is suggested to be critical although further research is needed to fully understand the process [23]. Significantly, higher proliferation was found in patients with trauma-related tears than in those with chronic tears. Patients in this study underwent surgery, including biopsy harvesting, 20-50 days after the traumatic event and it is likely that the acute, inflammatory response of the tendon tissue was replaced by the proliferative phase in some cases. Interestingly, no correlation between tendon degeneration, as determined with the Bonar score, and proliferation index was found. This indicates that other factors determine the proliferation capability and not necessarily the degree of degeneration. However, a positive correlation between more extensive tendon degeneration and higher inflammatory and apoptosis indices was found. The positive relationship between increased levels of degeneration and apoptosis was first described by Yuan et al. [49], who moreover postulated excessive apoptosis as a primary cause of tendinopathy and tearing within the supraspinatus tendon. Results from recent studies have challenged this and in a study on supraspinatus tendinosis, Scott et al. concluded that apoptosis might play a secondary role in more advanced stages of tendinopathy, such as remodelling after tissue tearing [41]. The findings of the present study are consistent with the latter. In contrast to other publications reporting increased apoptotic index in patient with higher degree of tendon degeneration [3, 26, 27, 45, 49], significantly increased apoptotic index (p53) was found in those with trauma-related tears compared to those with chronic tears. Therefore, apoptosis in trauma-related rotator cuff tears is suggested to be associated with tendon tissue injury in addition to tendon degeneration.

Acute tendon rupture may possibly initiate bleeding although tendons are poorly vascularised. A positive haemosiderin labelling was, however, only found in one-third of the biopsies from the trauma-related tears in this study. Parts of the rotator cuff is scarcely supplied with blood and most likely, a haemorrhage is not obligate in the central less vascularised critical zone $[5,7,25]$, in contrast to when an evulsion-like rupture occurs leaving a bleeding, bare footprint. Still, associated bleeding with increased healing potential is one major argument to support early repair for acute, trauma-related tears. The present results rather suggest that a trauma-related rotator cuff tear in a previously symptom-free shoulder is not necessarily associated with bleeding.

The prospective design and the well-defined study group of previously asymptomatic patients with traumarelated tears and acute symptoms are major strengths of this study. Histopathological tendon findings have to our knowledge not been reported from a respective cohort. One limitation is that the Bonar score was originally developed for patellar tendinopathy. Although it has been validated for use in rotator cuff tendinopathy [28], it has to our knowledge not been used on trauma-related cuff tears. The Bonar score findings should, therefore, be interpreted with some caution. Second, there are many other inflammatory markers than pan-leucocyte marker CD45 and the use of other markers may present different outcomes with regard to inflammation. Similarly, physiological and pathological apoptosis are highly complex processes and the p53 index is only one of several available techniques. Still, we based our selection of markers on previous rotator cuff or tendon-related studies and a previously reported valid reproducibility. Third, even though all the patients in the study group were subjectively shoulder healthy before the trauma, the preinjury tendon status was not known. It cannot be excluded that some of the patients had asymptomatic tears prior to their trauma. Still, a partial repair due to severe retraction of the supraspinatus tendon was only necessary in one patient. Sensitivity analyses were conducted with and without this patient and did not affect the outcome (Supplementary material).

Previously, asymptomatic patients suffering from trauma-related rotator cuff tears need to be informed about a likely underlying tendon degeneration and the risk of non-healing despite early surgical repair. Therefore, other factors such as tear type and size, shoulder function and patient's activity level might be more important than a trauma-related onset of symptoms when it comes to treatment decision making in this group of patients.

\section{Conclusion}

The results of this study suggest that acute, trauma-related rotator cuff tears in previously asymptomatic patients have pre-existing tissue degeneration, and thereby likely tissue weakening, comparable to what is found in chronic, nontraumatic tears.

Supplementary Information The online version contains supplementary material available at https://doi.org/10.1007/s00167-022-06884-w. 
Acknowledgements The authors thank Pehr Rissler, MD Ph.D. for all histological and immunohistochemical analyses and for methodological advices and physiotherapists Anna Lönnberg and Madelaine Andersson for performing physical examination within the Acute Shoulder Assessment Project. We also thank Anna Åkesson, statistician at Lund University for statistical advice, Simon Bossmar, MD for data preparation, and Petra Petersson, Constanze Pilgram, and Henrik Ahlborg at the Department of Orthopaedics, Skane university hospital, for their contribution in collecting patients for the reference group.

Author contributions KEA (orthopaedic surgeon) participated in the design of the study, prepared databases, carried out the calculations and wrote the first draft. $\mathrm{HH}$ (orthopaedic surgeon, associate professor) participated in the design of the study and participating in drafting the manuscript, KL (orthopaedic surgeon, associate professor) supervised the study, participated in the design of the study and participating in drafting the manuscript. RF (physical therapist, associate professor) supervised the study, participated in the design of the study as well as the drafting of the manuscript and takes responsibility for the scientific content. All the authors read and approved the final form of the manuscript.

Funding Open access funding provided by Lund University. The study was supported by grants from Stig og Ragna Gorthon Research Foundation and Thelma Zoegas Foundation, Helsingborg, Sweden.

\section{Declarations}

Conflict of interest The authors declare that they have no conflict of interests.

Ethical standards This study was approved by the Regional Ethical Review Board in Lund, Sweden, Registration Number 2011/119, 2015/36, 2016/796.

Informed consent All the patients signed a consent form giving permission to use their anonymous data for research.

Open Access This article is licensed under a Creative Commons Attribution 4.0 International License, which permits use, sharing, adaptation, distribution and reproduction in any medium or format, as long as you give appropriate credit to the original author(s) and the source, provide a link to the Creative Commons licence, and indicate if changes were made. The images or other third party material in this article are included in the article's Creative Commons licence, unless indicated otherwise in a credit line to the material. If material is not included in the article's Creative Commons licence and your intended use is not permitted by statutory regulation or exceeds the permitted use, you will need to obtain permission directly from the copyright holder. To view a copy of this licence, visit http://creativecommons.org/licenses/by/4.0/.

\section{References}

1. Aagaard KE, Lunsjö K, Frobell R (2019) Early repair of traumarelated full-thickness rotator cuff tears does not eliminate the problem of healing failure. Bone Joint J 101-B:603-609

2. Abrahamsson SO, Lohmander S (1996) Differential effects of insulin-like growth factor-I on matrix and DNA synthesis in various regions and types of rabbit tendons. J Orthop Res 14:370-376

3. Benson RT, McDonnell SM, Knowles HJ, Rees JL, Carr AJ, Hulley PA (2010) Tendinopathy and tears of the rotator cuff are associated with hypoxia and apoptosis. J Bone Joint Surg Br 92:448-453

4. Blomgran P, Hammerman M, Aspenberg P (2017) Systemic corticosteroids improve tendon healing when given after the early inflammatory phase. Sci Rep 7:12468

5. Brooks CH, Revell WJ, Heatley FW (1992) A quantitative histological study of the vascularity of the rotator cuff tendon. J Bone Joint Surg Br 74:151-153

6. Chona DV, Lakomkin N, Lott A, Workman AD, Henry AC, Kuntz AF et al (2017) The timing of retears after arthroscopic rotator cuff repair. J Shoulder Elbow Surg 26:2054-2059

7. Codman EA, Akerson IB (1931) The pathology associated with rupture of the supraspinatus tendon. Ann Surg 93:348-359

8. Dean BJF, Snelling SJB, Dakin SG, Murphy RJ, Javaid MK, Carr AJ (2015) Differences in glutamate receptors and inflammatory cell numbers are associated with the resolution of pain in human rotator cuff tendinopathy. Arthritis Res Ther 17:176-176

9. Fabiś J, Kordek P, Bogucki A, Mazanowska-Gajdowicz J (2000) Function of the rabbit supraspinatus muscle after large detachment of its tendon: 6-week, 3-month, and 6-month observation. J Shoulder Elbow Surg 9:211-216

10. Fearon A, Dahlstrom JE, Twin J, Cook J, Scott A (2014) The Bonar score revisited: region of evaluation significantly influences the standardized assessment of tendon degeneration. J Sci Med Sport 17:346-350

11. Fukuda H (2000) Partial-thickness rotator cuff tears: a modern view on Codman's classic. J Shoulder Elbow Surg 9:163-168

12. Gelberman RH, Steinberg D, Amiel D, Akeson W (1991) Fibroblast chemotaxis after tendon repair. J Hand Surg Am 16:686-693

13. Gutman MJ, Joyce CD, Patel MS, Kirsch JM, Gutman BS, Abboud JA et al (2021) Early repair of traumatic rotator cuff tears improves functional outcomes. J Shoulder Elbow Surg 30:2475-2483

14. Hammerman M, Aspenberg P (1985) Eliasson P (2014) Microtrauma stimulates rat Achilles tendon healing via an early gene expression pattern similar to mechanical loading. J Appl Physiol 116:54-60

15. Hantes ME, Ono Y, Raoulis VA, Doxariotis N, Venouziou A, Zibis A et al (2018) Arthroscopic single-row versus double-row suture bridge technique for rotator cuff tears in patients younger than 55 years: a prospective comparative study. Am J Sports Med 46:116-121

16. Heuberer PR, Pauzenberger L, Gruber MS, Ostermann RC, Hexel M, Laky B et al (2020) Delaminated rotator cuff tears showed lower short-term retear rates after arthroscopic double-layer repair versus bursal layer-only repair: a randomized controlled trial. Am J Sports Med 48:689-696

17. Hope M, Saxby TS (2007) Tendon healing. Foot Ankle Clin 12:553-567

18. Iannotti JP, Zlatkin MB, Esterhai JL, Kressel HY, Dalinka MK, Spindler KP (1991) Magnetic resonance imaging of the shoulder. Sensitivity, specificity, and predictive value. J Bone Joint Surg Am 73:17-29

19. Kannus P, Józsa L (1991) Histopathological changes preceding spontaneous rupture of a tendon. A controlled study of 891 patients. J Bone Joint Surg Am 73:1507-1525

20. Kapetanos G (1982) The effect of the local corticosteroids on the healing and biomechanical properties of the partially injured tendon. Clin Orthop Relat Res 163:170-179

21. Kinra P, Malik A (2020) Ki 67: Are we counting it right? Indian J Pathol Microbiol 63:98-99

22. Koo TK, Li MY (2016) A guideline of selecting and reporting intraclass correlation coefficients for reliability research. J Chiropr Med 15:155-163

23. Landén NX, Li D, Ståhle M (2016) Transition from inflammation to proliferation: a critical step during wound healing. Cell Mol Life Sci 73:3861-3885 
24. Lawrence RL, Moutzouros V, Bey MJ (2019) Asymptomatic rotator cuff tears. JBJS Rev 7:e9-e9

25. Lohr JF, Uhthoff HK (1990) The microvascular pattern of the supraspinatus tendon. Clin Orthop Relat Res 254:35-38

26. Lundgreen K, Lian OB, Engebretsen L, Scott A (2011) Tenocyte apoptosis in the torn rotator cuff: a primary or secondary pathological event? Br J Sports Med 45:1035-1039

27. Lundgreen K, Lian OB, Scott A, Nassab P, Fearon A, Engebretsen L (2014) Rotator cuff tear degeneration and cell apoptosis in smokers versus nonsmokers. Arthroscopy 30:936-941

28. Maffulli N, Longo UG, Franceschi F, Rabitti C, Denaro V (2008) Movin and Bonar scores assess the same characteristics of tendon histology. Clin Orthop Relat Res 466:1605-1611

29. Mall NA, Lee AS, Chahal J, Sherman SL, Romeo AA, Verma NN et al (2013) An evidenced-based examination of the epidemiology and outcomes of traumatic rotator cuff tears. Arthroscopy 29:366-376

30. Mikolyzk DK, Wei AS, Tonino P, Marra G, Williams DA, Himes RD et al (2009) Effect of corticosteroids on the biomechanical strength of rat rotator cuff tendon. J Bone Joint Surg Am 91:1172-1180

31. Milgrom C, Schaffler M, Gilbert S, Holsbeeck MV (1995) Rotator-cuff changes in asymptomatic adults. The effect of age, hand dominance and gender. J Bone Joint Surg Br 77(2):296-298

32. Millar NL, Wei AQ, Molloy TJ, Bonar F, Murrell GAC (2009) Cytokines and apoptosis in supraspinatus tendinopathy. $\mathrm{J}$ Bone Joint Surg Br 91:417-424

33. Minagawa H, Yamamoto N, Abe H, Fukuda M, Seki N, Kikuchi K et al (2013) Prevalence of symptomatic and asymptomatic rotator cuff tears in the general population: from mass-screening in one village. J Orthop 10:8-12

34. Mukovozov I, Byun S, Farrokhyar F, Wong I (2013) Time to surgery in acute rotator cufftear: a systematic review. Bone Joint Res 2:122-128

35. Nakamura $\mathrm{H}$, Gotoh $\mathrm{M}$, Mitsui $\mathrm{Y}$, Honda $\mathrm{H}$, Ohzono $\mathrm{H}$, Shimokobe $\mathrm{H}$ et al (2016) Factors affecting clinical outcome in patients with structural failure after arthroscopic rotator cuff repair. Arthroscopy 32:732-739

36. Oh LS, Wolf BR, Hall MP, Levy BA, Marx RG (2007) Indications for rotator cuff repair: a systematic review. Clin Orthop Relat Res 455:52-63

37. Pauly S, Stahnke K, Klatte-Schulz F, Wildemann B, Scheibel M, Greiner S (2015) Do patient age and sex influence tendon cell biology and clinical/radiographic outcomes after rotator cuff repair? Am J Sports Med 43:549-556

38. Pogorzelski J, Erber B, Themessl A, Rupp M-C, Feucht MJ, Imhoff AB et al (2021) Definition of the terms "acute" and "traumatic" in rotator cuff injuries: a systematic review and call for standardization in nomenclature. Arch Orthop Trauma Surg 141:75-91

39. Puzzitiello RN, Patel BH, Forlenza EM, Nwachukwu BU, Allen AA, Forsythe B et al (2020) Adverse impact of corticosteroids on rotator cuff tendon health and repair: a systematic review of basic science studies. Arthrosc Sports Med Rehabil 2:161-169

40. Ro KH, Park JH, Lee SH, Song DI, Jeong HJ, Jeong WK (2015) Status of the contralateral rotator cuff in patients undergoing rotator cuff repair. Am J Sports Med 43:1091-1098

41. Scott A, Cook JL, Hart DA, Walker DC, Duronio V, Khan KM (2007) Tenocyte responses to mechanical loading in vivo: a role for local insulin-like growth factor 1 signaling in early tendinosis in rats. Arthritis Rheum 56:871-881

42. Spross C, Behrens G, Dietrich TJ, Olaf Kim CH, Puskas GJ, Zdravkovic V et al (2019) Early arthroscopic repair of acute traumatic massive rotator cuff tears leads to reliable reversal of pseudoparesis: clinical and radiographic outcome. Arthroscopy. https://doi.org/10.1016/j.arthro.2018.08.048

43. Tashjian RZ (2012) Epidemiology, natural history, and indications for treatment of rotator cuff tears. Clin Sports Med 31:589-604

44. Tatari H, Kosay C, Baran O, Ozcan O, Ozer E (2001) Deleterious effects of local corticosteroid injections on the Achilles tendon of rats. Arch Orthop Trauma Surg 121:333-337

45. Tuoheti Y, Itoi E, Pradhan RL, Wakabayashi I, Takahashi S, Minagawa $\mathrm{H}$ et al (2005) Apoptosis in the supraspinatus tendon with stage II subacromial impingement. J Shoulder Elbow Surg 14:535-541

46. Via AG, De Cupis M, Spoliti M, Oliva F (2013) Clinical and biological aspects of rotator cuff tears. Muscles Ligaments Tendons J 3:70-79

47. Xue M, Jackson CJ (2015) Extracellular matrix reorganization during wound healing and its impact on abnormal scarring. Adv Wound Care (New Rochelle) 4:119-136

48. Yamamoto A, Takagishi K, Osawa T, Yanagawa T, Nakajima D, Shitara $\mathrm{H}$ et al (2010) Prevalence and risk factors of a rotator cuff tear in the general population. J Shoulder Elbow Surg 19:116-120

49. Yuan J, Murrell GAC, Wei A-Q, Wang M-X (2002) Apoptosis in rotator cuff tendonopathy. J Orthop Res 20:1372-1379

50. Zhaeentan S, Von Heijne A, Stark A, Hagert E, Salomonsson B (2016) Similar results comparing early and late surgery in open repair of traumatic rotator cuff tears. Knee Surg Sports Traumatol Arthrosc 24:3899-3906

Publisher's Note Springer Nature remains neutral with regard to jurisdictional claims in published maps and institutional affiliations. 